\title{
PENANGANAN BANJIR DENGAN KOLAM RETENSI (RETARDING BASIN) DI KELURAHAN GANDUS KOTA PALEMBANG
}

\author{
Reni Andayani ${ }^{1)}$, Bahder Djohan ${ }^{2)}$, Kemas Aditya Arlingga ${ }^{3)}$ \\ Program Studi Teknik Sipil Fakultas Teknik - UTP
}

\begin{abstract}
ABSTRAK
Banjir merupakan bencana alam yang terjadi di kawasan banyak dialiri oleh sungai alam atau akibat ketidakmampuan saluran suatu wilayah menampung tingginya curah hujan di wilayah tersebut. Kota Palembang terbagi atas 16 Kecamatan dan 107 Kelurahan, salah satu Kelurahan yang rawan banjir adalah Kelurahan Gandus. Dalam mengatasi permasalahan banjir yang terjadi di Kelurahan Gandus, Pemerintah Kota Palembang telah merencanakan untuk dilakukan pembangunan kolam retensi.

Penelitian mengambil lokasi di Kelurahan Gandus Kecamatan Gandus Kota Palembang, pada sungai soak batang yang merupakan bagian dari DAS Gandus. Metode penelitian yang digunakan adalah deskriptif kuantitatif. Data curah hujan yang digunakan 10 tahun terakhir dari $2006-2015$. Analisis perhitungan debit banjir menggunakan metode HSS Nakayasu, untuk analisis kolam tampungan menggunakan metode Muskingum.

Berdasarkan hasil analisis debit banjir yang terjadi pada sungai soak batang sebesar $57,268 \mathrm{~m}^{3} / \mathrm{dtk}$ untuk kala ulang 10 tahun, kapasitas sungai soak batang sebesar $4,22 \mathrm{~m}^{3} / \mathrm{dtk}$ dan volume kapasitas kolam tampungan sebesar $68.015,308 \mathrm{~m}^{3}$. Pintu air yang dibutuhkan sebanyak 2 buah dengan lebar total pintu rencana 1,10 meter dan tinggi 2 meter.
\end{abstract}

Kata kunci : Banjir, Kolam Retensi, HSS Nakayasu, Pintu Romijn

Abstract :Flooding is a natural disaster that occurred in many areas by rivers or drains inability to occummudate the rainfall in the area. Palembang city consist of 16 District and 107 Village Gandus. In order to solve this problem, the government of Palembang city have planning to conduct the construction of retarding basin.

The researcher has researched at Gandus Village, Gandus District, Palembang City. Exactly in soak batang river that ia a part of DAS Gandus. Methodology of research is descriptive quantitative. Rainfall data were used the last 10 years from 2006 - 2015. Analytical calculation of flood discharge used HSS Nakayasu Method, for analysis the storage pand used Muskingum Method. Based on the result of analysis, flood discharge that accured in the soak batang river is $57,268 \mathrm{~m}^{3} / \mathrm{s}$ for 10 years, the capacity of the soak batang river is $4,22 \mathrm{~m}^{3} / \mathrm{s}$ and the voume of storage pond capacity is $68.015,308 \mathrm{~m}^{3}$. Sluice required as much as 2 pieces with a total width of planning door 1,10 meters and height 2 meters.

Keywords : Flood, Retarding Basin, HSS Nakayasu, Romijn Door 


\section{PENDAHULUAN}

\section{Latar Belakang}

Banjir merupakan bencana alam yang terjadi di kawasan yang banyak dialiri oleh sungai atau akibat ketidakmampuan saluran suatu wilayah menampung tingginya curah hujan di wilayah tersebut serta akibat genangan air sungai yang disebabkan oleh pasang surut. Banjir juga dapat terjadi akibat kurangnya kesadaran masyarakat untuk menjaga lingkungannya, seperti membuang sampah sembarangan dan penebangan liar.

Kota Palembang terbagi atas 16 Kecamatan dan 107 Kelurahan. Salah satu kecamatan yang rawan banjir adalah Kecamatan Gandus. Pada musim penghujan sering terjadi banjir yang diakibatkan oleh curah hujan yang tinggi dan luapan sungai. Salah satu Kelurahan yang ada di Kecamatan Gandus yang rawan banjir adalah Kelurahan Gandus. Salah satu sungai yang melintasi Kelurahan Gandus adalah sungai SoakBatang yang memiliki lebar \pm 7 meter dan merupakan anak sungai musi. Setiap kali terjadi curah hujan tinggi sungai tersebut meluap sehingga banyak lahan persawahan tergenang yang mengakibatkan tidak dapat difungsikan lahan tersebut sebagaimana mestinya. Faktor lain secara topografi wilayah tersebut relatif landai sehingga laju air menjadi lambat. Faktor perubahan tata guna lahan juga mempengaruhi terjadinya banjir, lahan resapan maupun rawa banyak dilakukan penimbunan dan dibangun permukiman maupun pabrik.Dalam mengatasi permasalahan banjir yang terjadi di wilayah Gandus, Pemerintah Kota Palembang telah merencanakan untuk dilakukan pembangunan kolam retensi (RTRW Kota Palembang 2012-2032 ; 2012). Kolam retensi yang akan dibangun berfungsi untuk menggantikan peran lahan resapan yang dijadikan lahan tertutup/perumahan/pabrik maka fungsi resapan dapat digantikan dengan kolam retensi. Fungsi dari kolam retensi iniadalah menampung air hujan langsung dan luapan sungai, sehingga kolam retensi ini perlu ditempatkan pada bagian yang terendah dari lahan. Karena itu perlu dilakukan penelitian analisis penanganan banjir untuk mengetahui debit banjir dan luasan kolam retensi pada Kelurahan Gandus. .

\section{Permasalahan}

Berdasarkan latar belakang permasalahan ini, maka akan dikaji masalah penanganan banjir dengan kolam retensi di kelurahan pulokerto yaitu sebagai berikut :

1. Berapakah debit puncak DAS Soak Batang?

2. Berapakah kapasitas sungai Soak Batang ?

3. Berapakah dimensi pintu air yang dibutuhkan?

\section{TINJAUAN PUSTAKA Kolam Retensi}

Kolam retensi adalah suatu bak atau kolam yang dapat menampung atau meresapkan air sementara yang terdapat di dalamnya. Kolam retensi dibagi menjadi 2 macam tergantung dari bahan pelapis dinding dan dasar kolam, yaitu kolam alami dan kolam buatan. Kolam alami adalah kolam retensi berbentuk cekungan atau bak resapan yang sudah terbentuk secara alami dan dapat dimanfaatkan baik pada kondisi aslinya ataudilakukan penyesuaian. Kolam buatan atau kolam non alami adalah kolam retensi yang dibuat sengaja didesain dengan bentuk dan kapasitas tertentu pada lokasi yang telah direncanakan sebelumnya dengan lapisan material yang kaku, seperti beton.

\section{Analisa Hidrologi Siklus Hidrologi}

Konsep siklus hidrologi merupakan hal yang sangat penting, karena air (baik air permukaan maupun air tanah) bagian dari siklus hidrologi. Siklus hidrologi dimulai dengan terjadinya panas matahari yang sampai permukaan bumi, sehingga menyebabkan penguapan. Akibat penguapan ini terkumpul massa uap air, yang dalam kondisi atmosfer tertentu dapat membentukawan. Akibat dari berbagai sebab klimatologis awan tersebut dapat menjadi awan yang potensial menimbulkan hujan.

\section{Analisa Curah Hujan Rencana}

Hujan merupakan komponen yang sangat penting dalam analisis hidrologi. Pengukuran hujan dilakukan selama 24 jam baik secara manual maupun otomatis, dengan cara ini berarti hujan yang diketahui adalah hujan total yang terjadi selama satu hari. Dalam analisa 
digunakan curah hujan rencana, hujan rencana yang dimaksud adalah hujan harian maksimum yang akan digunakan untuk menghitung intensitas hujan, kemudianintensitas ini digunakan untuk mengestimasi debit rencana.

\section{Analisa Curah Hujan Rencana}

Analisa frekuensi dapat diartikan sebagai suatu cara untuk memprediksi suatu besaran curah hujan di masa yang akan dating dengan menggunakan data curah hujan di masa yang lalu berdasarkan suatu pemakaian distribusi frekuensi. Dalam ilmu statistic dikenal beberapa macam distribusi frekuensi yang banyak digunakan dalam bidang hidrologi. Berikut empat macam jenis distribusi frekuensi yang paling banyak digunakan dalam bidang hidrologi distribusidigunakan dalam bidang hidrologi distribusi Normal, Log Normal, Gumbel, Pearson, dan log Pearson.

\section{Uji Distribusi Probabilitas Metode Chi-Kuadrat}

Rumus yang digunakan dalam perhitungan dengan metode uji chi-kuadrat sebagai berikut :

$X^{c}=\sum_{\mathrm{i}=1}^{\mathrm{n}} \frac{\left(\mathrm{O}_{\mathrm{r}}-\mathrm{E}_{\mathrm{r}}\right)^{2}}{\mathrm{E}_{\mathrm{r}}}$

Derajat nyata atau derajat kepercayaan

(a) tertentu yang sering diambil adalah 5\%. Derajat kebebasan (Dk) dihitung dengan rumus:

$$
\begin{aligned}
& \mathrm{Dk}=\mathrm{K}-(\mathrm{p}+1) . \\
& \mathrm{K}=1+3,3 \log \mathrm{n}
\end{aligned}
$$

Selanjutnya distribusi probabilitas yang dipakai untuk menentukan curah hujan rencana adalah distribusi probabilitas yang mempunyai simpangan maksimum terkecildan lebih kecil dari simpangan kritis atau dirumuskan sebagai berikut :

$$
\gamma^{2}<\gamma^{2}+
$$

\section{Intensitas Hujan Rencana}

Intensitas curah hujan adalah tinggi atau kedalaman air hujan persatuan waktu. Sifat umum hujan adalah makin singkat hujan berlangsung intensitasnya cenderung makin tinggi dan makin besar periode ulangnya makin tinggi pula intensitasnya.

$$
I=\frac{R_{24}}{24}\left(\frac{24}{t}\right)^{\frac{2}{3}}
$$

\section{Koefisien Pengaliran (C)}

Koefisien pengaliran adalah perbandingan antara tinggi aliran dan tinggi hujan untuk jangka waktu cukup panjang. Faktor utama yang mempengaruhi koefisien adalah laju infiltrasi tanah, kemiringan lahan, tanaman penutup tanah, dan intensitas hujan. Selain itu juga tergantung pada sifat dan kondisi tanah, air tanah, derajad kepadatan tanah, porositas tanah, dan simpanan depresi. Nilai koefesien C merupakan kombinasi dari beberapa faktor yang dapat dhitung dengan persamaan berikut :

\section{Analisa Debit Banjir HSS Nakayasu}

Nakayasu (1950) telah menyelidiki hidrograf satuan di Jepang dan memberikan seperangkat persamaan untuk membentuk suatu hidrograf satuan sebagai berikut :

Waktu kelambatan $(t g)$

Untuk $\mathrm{I},<15 \mathrm{~km}: \mathrm{tg}_{\mathrm{g}}-0,4+0,058 \mathrm{~T}$

Waktu puncak dan debit puncak hidrograf satuan sintetis dirumuskan sebagai

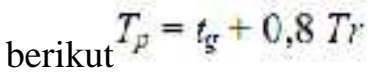

Waktu puncak

$T p=t g+0,8 \mathrm{Tr}$

Debit puncak hidrograf satuan sintesis dirumuskan sebagai berikut :

$$
\mathrm{Q}_{\mathrm{F}}-\frac{1}{3,6} \times A x R_{\mathrm{D}} x \frac{1}{\left(0,3 \times t_{p} x t_{0,3}\right)}
$$

Bagian lengkung naik $(0<\mathrm{t}<\mathrm{tp})$

$$
Q=Q_{p} x\left(\frac{t}{t_{p}}\right)^{2,4}
$$

Bagian lengkungan turun

$$
\begin{aligned}
& \text { - Jika } t p<t<t_{0,3} \\
& Q=Q_{p} \times 0.3^{\frac{t-t_{p}}{t_{0,3}}}
\end{aligned}
$$


- Jika $p=1>10.3$

$$
Q=Q_{p} \times 0,2^{\frac{i-t_{p}+0,5 x t_{0,3}}{15 r_{0,3}}}
$$

- Jika $t>1,5 i_{0,3}$

$$
Q=Q_{p} \times 0,3^{\frac{t-t_{3}+05 \times t_{2,3}}{2 \times t_{0,3}}}
$$

\section{Analisa Kapasitas Sungai}

Perhitungan kapasitas sungai menggunakan rumus:

$$
Q=\frac{1}{n} \times A \times R^{2 / 3} \times S^{1 / 2}
$$

$$
\begin{aligned}
& \text { Q - kapasitas debit }\left(\mathrm{m}^{2} / \mathrm{dk}\right) \text {. } \\
& \text { il - koefisien kekasarau Manning. } \\
& \mathrm{R}-\mathrm{Jari-jari} \mathrm{hidrolik}(\mathrm{m}) \text { dimana } \mathrm{R}=\frac{\mathrm{A}}{\mathrm{P}} \\
& \text { S = kemiringan dasar saluran. } \\
& A=\text { luas penampang basah }\left(\mathrm{m}^{2}\right) \text {. } \\
& \mathrm{P} \quad \text { - keliling penampang basah (m). }
\end{aligned}
$$

\section{Analisa Kebutuhan Lebar Pintu}

Perencanaan menggunakan pintu Romijn karena lebih ekonomis dibanding pintu air.

a)Lebar efektif pintu Romijn (Kriteria Perencanaan, 1986)

$$
Q=C \times C_{v} \times \frac{2}{3} \times \sqrt{\left(\frac{2}{3} \times g\right)} \times B \times h_{1}^{1,5}
$$

b) Lebar total pintu Romijn yang direncanakan:

$$
\mathrm{Bp}=\mathrm{be}+(\mathrm{Kp}+\mathrm{Ka}) \times \mathrm{H}_{\operatorname{Max}}
$$

\section{METODOLOGI PENELITIAN}

\section{Lokasi Penelitian}

Penelitian dimulai pada bulan mei dan studi kasus dilaksanakan pada kawasan Kelurahan Gandus Kecamatan Gandus Kota Palembang. Berikut peta lokasi kawasan tersebut :

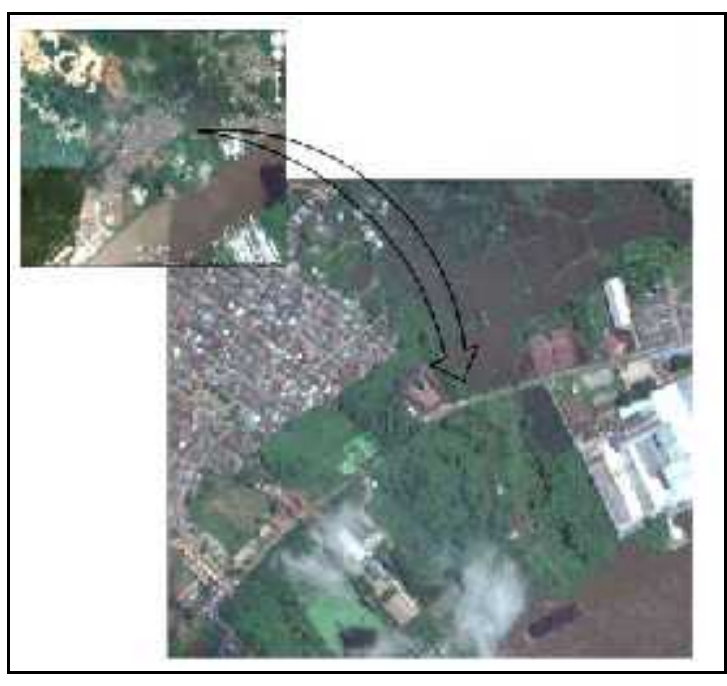

\section{Metode Pengumpulan Data}

Metode yang digunakan dalam pengolahan data penulisan ini adalah metode kuantitatif deskriptif, yaitu metode perhitungan dan penjabaran hasil pengolahan data dilapangan dari lokasi yang ditinjau.

\subsection{Pengumpulan Data}

Data yang dikumpulkan adalah data primedan sekunder. Data primer diperoleh dengacara survey langsung ke lapangan sedangkadata sekunder diperoleh dari instansi terkait.

(1) Data primer

Berupa data :

-Data Profil Sungai

Berupa data :

- Lebar sungai yang diukur dengan meteran.

- Panjang sungai yang diukur dengan meteran dengan jarak

per 100 meter.

- Kedalaman sungai yang diukur dengan cara menancapkan

kayu atau bambu hingga kedasar sungai.

(2). Data sekunder

Berupa data :

-Data curah hujan selama 10 tahun terakhir yaitu dari tahun 2006

hingga 2015 yang diperoleh dari Badan Meteorologi,Klimatologi dan Geofisika (BMKG). 
-Peta topografi dan peta tata guna lahan yang diperoleh dariBadan Perencanaan Pembangunan Daerah (BAPEDDA) Kota Palembang.

\section{Pengolahan Data}

Data yang diperoleh dari hasil survei lapangan dan data-data yangdidapat dari instansi pemerintah, kemudian diolah dengan menggunakananalisa hidrologi Distribusi Log Pearson III Selanjutnya melakukan analisadebit puncak sungai dengan menggunakan Metode Rasional.

\section{Analisa Data}

Dari hasil pengolahan, akan dilakukan analisa data sehingga dapat diperoleh kesimpulan akhir yang berarti. Beberapa analisa tersebut berupa:

a. Intensitas curah hujan harian maksimum b. Analisis kapasitas kolam tampungan

c. Analisis kebutuhan lebar pintu

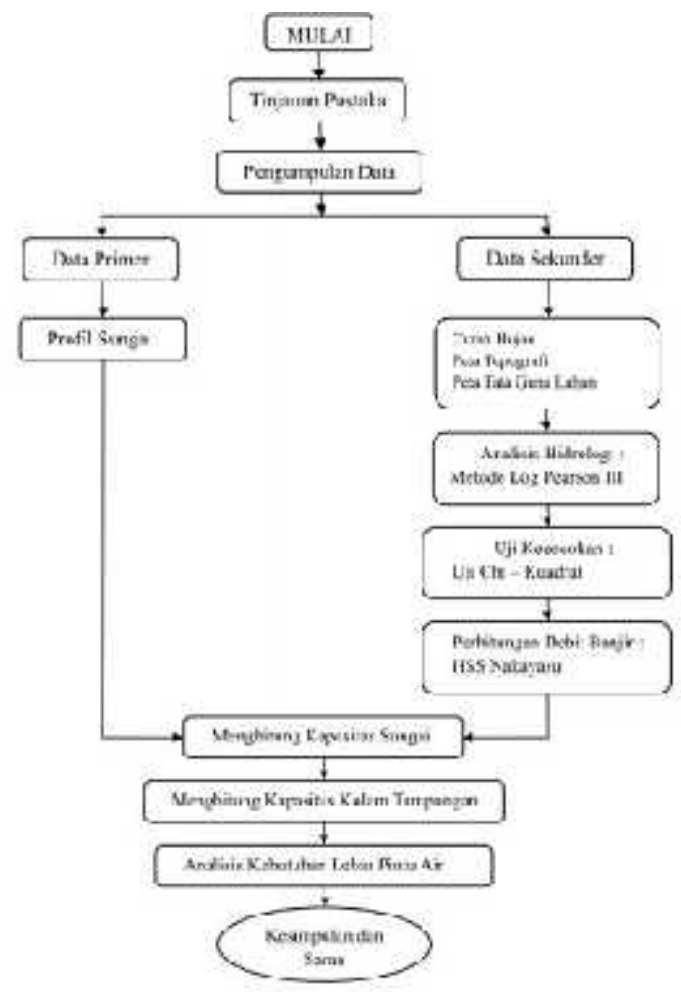

Bagan Alir Penelitian

\section{ANALISIS DAN PEMBAHASAN Analisis Hidrologi}

Curah hujan maksimum diperoleh dari Badan Meteorologi, Klimatologi dan Geofisika Kelas I Kenten untuk wilayah Stasiun Gandus selama 10 tahun yaitu dari tahun 2006 hingga 2015, sehingga diperoleh data seperti pada tabel dibawah ini :

Tabel Data Curah Hujan Tahunan Maksimum

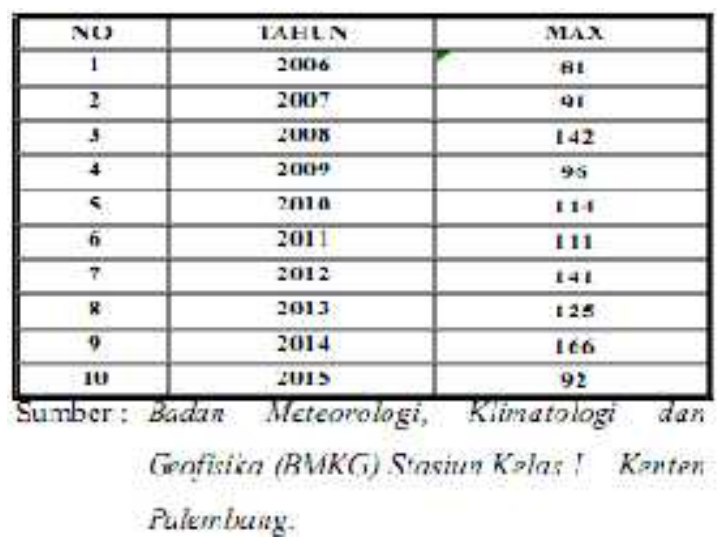

\section{Analisis Frekuensi Curah Hujan}

Dari hasil perhitungan, selanjutnyaditentukan jenis sebaran yang sesuai.

Dalam penentuan jenis sebaran diperlukan faktor - faktor sebagai berikut :

$$
\begin{aligned}
& \text { 1. Koefisian Skewness (Cs) = } \\
& \frac{n \sum(x i-x \text { rerat } a)^{3}}{(n-1)(n-2) s^{3}}=\frac{10 \times 304.4 .0 \varepsilon}{9 \times 8 \times 2+25 y^{3}}=\mathbf{0 , 5 4 6}
\end{aligned}
$$

2. Simpangan Baku $(\mathrm{S})=\sqrt{\frac{\sum\left(x i-X^{*}+r^{2} a t a\right)^{2}}{n-1}}$

$$
=\sqrt{\frac{6736.9}{9}}=27,359
$$

3. Koefisien Kurtosis $(\mathrm{Ck})-\frac{\frac{1}{n} \sum(x i-X-\text {-erata })^{2}}{s^{4}}$

$$
=\frac{\frac{1}{10} \times 9519622,42}{27,359^{4}}=1,699
$$

4. Koefisien Variasi $(\mathrm{CV})=\frac{\mathrm{S}}{\text { Xrera:a }}=\frac{27.359}{115.9}$

$$
=0,230
$$


Pemilihan Jenis Distribusi

Tabel Perbandingan Syarat Distribusi dan Hasil Perhitungan

\begin{tabular}{|c|c|c|c|c|}
\hline no & Jaris Les:rbasi & S) & Hasl rerhiturgan & Ketsor zan \\
\hline$\therefore$ & Marm 2 & $\varepsilon=0$ & astero & Kurarg \\
\hline 2 & Dgharms & $a=3 C v+E r^{t}$ & \multirow{2}{*}{ 0s4everts } & \multirow{2}{*}{ Kulars } \\
\hline & & $\mathrm{G}=0 . \mathrm{xeA}$ & & \\
\hline 3 & af Pearnon if & $\underline{\theta}>0$ & 155922 & Mananum \\
\hline 4 & anise! & $8-1 .: 596$ & $0.526-2 .: 598$ & Kures \\
\hline & & 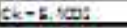 & $1.200-1.022$ & Kanera \\
\hline
\end{tabular}

Sumber: Hasil Perhitangan

\section{Distribusi Log Pearson III}

Tabel Analisis Curah Hujan Rencana dengan Distribusi Log Pearson III

\begin{tabular}{|c|c|c|c|c|c|c|}
\hline 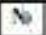 & Gole Ding & LogXrerata & k & $5 \log x$ & $\operatorname{Lat} \mathrm{S}_{\mathrm{r}}$ & $\mathrm{K}_{\mathrm{r}}(\mathrm{ng})$ \\
\hline 1 & 32 & .053 & $1302:$ & 21009 & $213+8$ & 153915 \\
\hline
\end{tabular}

Sumber: Hasil Pethitungar

\section{Pengujian Kecocokan Jenis Sebaran Metode Chi - Kuadrat}

Tabel Analisis Uji Distribusi Probabilitas Chi - Kuadrat Distribusi Log Pearson III

\begin{tabular}{|c|c|c|c|c|c|c|}
\hline$S_{D}$ & Kay L Lang & $\log x$ & kt & $3 \log x$ & $\log x$ & $x_{\text {s }\{\text { (nIn) }}$ \\
\hline 1 & 5 & 2012 & $0 . \mathrm{k} 2 \%$ & 0.006 & 2.125 & $191+109$ \\
\hline 2 & $=8$ & $=0: 1$ & 0.2665 & 0.4062 & $=0 \times 44$ & $115 . \mathrm{ns}$ \\
\hline 3 & 159 & 7042 & $.0 \times 40$ & $A \sin \theta$ & 7 aा $4 x$ & 104.101 \\
\hline 4 & 122 & 2013 & .08504 & 0.5009 & 1.9672 & 92.314 \\
\hline
\end{tabular}

Sumber ; I Iasil Perhiturgan

Berdasarkan tabel Distribusi Log Pearson III memiliki nilai $X^{2}<X 2 \mathrm{cr}$

atau distribusi tersebut dapat diterima.

\section{Analisis Intensitas Hujan}

a) Untuk periode ulang (T) 10 Tahun

$$
\begin{aligned}
& I=\frac{R_{24}}{24}\left(\frac{24}{t}\right)^{27} \\
& I=\frac{153.035}{24}\left(\frac{24}{20 / 60}\right)^{2 / 3}=175.181 \mathrm{~mm} / \mathrm{jam} .
\end{aligned}
$$

\section{Analisa Debit Banjir}

Perhitungan debit banjir yang digunakan pada penelitian ini adalah Hidrograf Satuan Sintesis Nakayasu. Berikut input data DAS Gandus : 1. Design Rainfall = Analisis curah hujan rencana $\times \mathrm{Qt}=153,035 \times 0,373=57,082$

2. Limpasan langsung $=$ Design rainfall $=$ $57,082 \mathrm{~m} 3 / \mathrm{dt}$ 3. Debit Puncak (Q) $=$ Limpasan langsung $(\mathrm{m} 3 \mathrm{p})+$ Base flow $(\mathrm{m} 3)=57,082+$ $0,186=57,268 \mathrm{~m} 3 / \mathrm{dt}$

\section{Analisis Kapasitas Sungai}

Dari perhitungan denganmenggunakan rumus manning didapat kapasitas sungai 4,22 m3/dt, dengan demikian kapasitas sungai tidak mampu menampung debit banjir yang terjadi.

\section{Analisis Kapasitas Kolam Tampungan}

Dari hasil perhitungan diperolehkumulatif aliran masuk Qt sebesar 68.015,308 $\mathrm{m}^{3}$

Dengan direncanakan kolam tampungan tanpa pompa serta kedalaman kolam direncanakan sedalam $2 \mathrm{~m}$, maka luasan kolam yang dibutuhkan sebesar $68.015,308 \mathrm{~m}^{3} / 2 \mathrm{~m}=$ $34.007,654 \mathrm{~m}^{2}$

Dengan hasil tersebut maka luasan lahan yang dibutuhkan sebesar 3,4 Ha.

\section{Analisis Kebutuhan Lebar Pintu Air}

a. Lebar efektif pintu

$$
\begin{aligned}
& \mathrm{B}=\frac{Q}{C_{n} \times C_{v} \times \frac{2}{3} \sqrt{\left(\frac{2}{3} \times g\right)} \times h_{1}^{1.5}} \\
& \mathrm{~B}=\frac{4,22}{1.03 \times 0.89 \times \frac{2}{3} \times \sqrt{\frac{2}{3} \times 9.81} \times 1.99^{1.5}} \\
& \mathrm{~B}=0,96 \mathrm{~m} \sim 1 \mathrm{~m}
\end{aligned}
$$

Dalam pelaksanaannya, kolam retensi memerlukan pintu masuk air (Inlet) dan pintu keluar air (Outlet), maka Direncanakan jumlah pintu Romijn sebanyak 2 buah.

b. Lebar pintu yang direncanakan :

$$
\begin{aligned}
\mathrm{Bp} & =1+(0.01+0.1) \times 0,5 \\
& =1,05 \mathrm{~m} \sim 1,10 \mathrm{~m}
\end{aligned}
$$

Dari hasil perhitungan diatas diperoleh lebar pintu romijn sebesar 1,10 meter.

\section{KESIMPULAN DAN SARAN Kesimpulan}

Berdasarkan hasil analisis yang telah dilakukan, maka didapat kesimpulan sebagai berikut :

1. Debit puncak yang terjadi pada periode 
kala ulang 10 tahun sebesar 57,268 m³/dtk. 2 . Kapasitas sungai Soak Batang sebesar $4,22 \mathrm{~m}^{3} / \mathrm{dtk}$.

3. Pintu air yang dibutuhkan sebanyak 2 buahdengan lebar efektif 1 meter, lebar pintu yang direncanakan 1,10 dan tinggi 2 meter.

\section{Saran}

Berdasarkan hasil uraian analisispenanganan banjir dengan kolam retensi (retarding basin) di Kelurahan Gandus Kota Palembang, dapat disarankan sebagai

berikut :

1. Perlu dilakukannya normalisasi pada sungai Soak Batang, agar dapatmemperbesar daya tampung dan dapat mengurangi debit banjir yang terjadi pada Kelurahan Pulokerto.

2. Bagi peneliti selanjutnya diharapkan dapat mengadakan penelitian yang lebih mendalam dan lebih luas, karena masih banyak wilayah Kecamatan Gandus yang terkena dampak banjir.

\section{DAFTAR PUSTAKA}

Astuti, Dkk. 2015, Analisis Kolam Retensi Sebagai Pengendalian Banjir Genangan di Kecamatan Payung Sekaki. Fakultas Teknik, Jurusan Teknik Sipil, Universitas Riau, Riau.

Dirjen Cipta Karya, 2008. Tata Cara Pembuatan Kolam Retensi dan Polder Dengan Saluran - saluran Utama. Departemen Pekerjaan Umum.

Kodoatie, Robert J. 2004. Pengelolaan Sumber Daya Terpadu. Andi. Yogyakarta.

Pemerintah Kota Palembang. 2011. Keadaan Geografis Kota Palembang. Pemerintah Kota Palembang. Palembang.

Pemerintah Kota Palembang. 2012, Rencana Tata Ruang Wilayah (RTRW) Kota Palembang Tahun 2012-2032. BAPPEDA Kota Palembang. Palembang.

Pramono, David. 2015, Perencanaan Kolam Retensi Sebagai Usaha Mereduksi Banjir (Studi Kasus : Kecamatan Medan Selayang Kelurahan Asam Kumbang,
(Skripsi), Fakultas Teknik, Jurusan Teknik Sipil, Universitas Sumatera Utara, Medan.

Rezkina, Dhaka. 2015, Analisis Penanganan Banjir Dengan Kolam Retensi (Retarding Basin) di Desa Blang Beurandang Kabupaten Aceh Barat. Fakultas Teknik, Jurusan Teknik Sipil, Universitas Sumatera Utara, Medan.

Suripin, Dr. Ir. M.Eng, Sistem Drainase Perkotaan yang Berkelanjutan. Andi. Yogyakarta.

Triarmodjo, Bambang. 2013, Hidrologi Terapan, Beta Offset, Yogyakarta.

Wesli. 2008, Drainase Perkotaan, Graha Ilmu. Yogyakarta. 